\title{
Preparation and Characterization of Polypropylene Grafted Halloysite and Their Compatibility Effect to Polypropylene/Halloysite Composite
}

\author{
Mingliang Du, Baochun Guo, ${ }^{\dagger}$ Mingxian LIU, and Demin JiA \\ Department of Polymer Materials and Engineering, South China University of Technology, \\ Guangzhou 510640, China
}

(Received May 19, 2006; Accepted August 8, 2006; Published September 21, 2006)

KEY WORDS Polypropylene / Halloysite / Compatibility / Composite /

[doi:10.1295/polymj.PJ2006038]

Ultrafine inorganics filled polymer composites have recently drawn many researchers' interests and developed rapidly for their superior properties, such as much higher mechanical properties, thermal stability and flame retardant properties, outstanding barrier properties and reduced costs. ${ }^{1-3}$ The dispersion of the fillers and interface between the filler and polymer matrix are crucial to the improvements in the properties of the composites. ${ }^{4-6}$ To accomplish them, generally speaking, the compatibilization between inorganics and polymers is necessary as the surface properties of the fillers are quite different from those of the polymers.

Compatibilization between the polyolefins and inorganics is specially challengable due to the great polarity discrepancy and chemical inert of the polyolefins. So far, many methods, including surface modification with the coupling agents such as silanes and utilization of polyolefin grafts as compatibilizers, have been reported to modify the surface properties of inorganic fillers to increase the compatibility of the fillers and polyolefins. ${ }^{7-11}$ As mentioned above, the polyolefins such as PP is chemically inert, the silanized fillers are not readily react with PP under the processing conditions. As a consequence, the interfacial bonding is not satisfactory. As for the alternative method, i.e. using grafts as compatibilizers, the reactivity of most commercialized graft such as maleic anhydride grafted PP (PP-g-MAH) towards to inorganics is not sufficient. Actually many authors suggested only secondary interactions such as hydrogen bonding present between the filler and PP-g-MAH.

The present work attempts to increase the compatibility between PP and halloysite, which is naturally occurred kaolinite with hollow nanotubular structure and capable of imparting PP higher thermal stability and flame retardancy, ${ }^{12}$ by grafting PP chains onto the surface of halloysite via a two-step method. The effectiveness of the grafting process and the PP grafted halloysite (g-halloysite) on the mechanical properties were examined.

\section{EXPERIMENTAL}

\section{Raw Materials}

The halloysite, grade of Ultrafine, were provided by Imerys Tableware Asia Limited, New Zealand. Brightness of $98.9 \%$ as measured by a Minolta CR300 using D65 light source. The elemental composition is as follows (wt \%): $\mathrm{SiO}_{2}, 49.5 ; \mathrm{Al}_{2} \mathrm{O}_{3}, 35.5 ; \mathrm{Fe}_{2} \mathrm{O}_{3}$, $0.29 ; \mathrm{TiO}_{2}, 0.09$. The specific area is approximately $28 \mathrm{~m}^{2} / \mathrm{g}$. Aminopropyltriethoxysilane, with tradename of Z6011, was manufactured by Dow Corning. PP-gMAH, Fusbond MD-353D with grafting percentage $2 \%$, was purchased from DuPont.

\section{Preparation of G-Halloysite}

In a typical pretreatment process of halloysites with the silane, ethanol water solution $(200 \mathrm{~mL})(95 \mathrm{vol} \%)$ was adjusted to $\mathrm{pH}$ value of 5 with acetic acid in a flask. Z6011 was added dropwise while stirring to yield final concentration of $2 \mathrm{wt} \%$. Five minutes should be allowed for hydrolysis. Then $100 \mathrm{~g}$ halloysite were added to the flask, agitating gently. The mixture was refluxed at $80^{\circ} \mathrm{C}$ for $3 \mathrm{~h}$. The halloysite were precipitated and then rinsed twice with ethanol water solution $(95 \mathrm{vol} \%)$. The modified halloysite were vacuum dried at $80^{\circ} \mathrm{C}$ for $5 \mathrm{~h}$ to remove the solvent residues and allow the further condensation take place. PP-g-MAH (7.5 g) was dissolved in xylene $(150 \mathrm{~mL})$ at $120^{\circ} \mathrm{C}$. The modified halloysite were added to the PP-g-MAH solution under stirring. The mixture was

${ }^{\dagger}$ To whom correspondence should be addressed (Tel: +86-20-8711-3374, Fax: +86-20-2223-6688, E-mail: psbcguo@ scut.edu.cn). 
reacted at $120^{\circ} \mathrm{C}$ for $3 \mathrm{~h}$. The halloysite was precipitated from the mixture and extracted three times with xylene. The modified halloysite (g-halloysite) were vacuum dried at $100{ }^{\circ} \mathrm{C}$ for $5 \mathrm{~h}$ to remove the solvent residue.

\section{Preparation of Model Compound}

PP-g-MAH $(10.0 \mathrm{~g})$ was dissolved in xylene $(200 \mathrm{~mL})$ at $120^{\circ} \mathrm{C} . \mathrm{Z} 6011(1.0 \mathrm{~g})$ was added to the PP-g-MAH solution under stirring. The mixture was reacted at $120^{\circ} \mathrm{C}$ for $3 \mathrm{~h}$. The product was precipitated from the mixture with ethanol. Unreacted silane and xylene was extracted by ethanol. The product was dried at $80^{\circ} \mathrm{C}$ for $5 \mathrm{~h}$ to remove the solvent residue.

\section{Preparation of PP Composites}

PP and halloysite or g-halloysite were blended using a twin-screw extruder. The temperature setting from the hopper to the die was $180 / 200 / 200 / 200 /$ $200 / 190^{\circ} \mathrm{C}$, and the screw speed was $100 \mathrm{rpm}$. The pelletized granules were dried for $5 \mathrm{~h}$ under $80^{\circ} \mathrm{C}$ and then injection molded under the temperature of $200^{\circ} \mathrm{C}$.

\section{Characterizations of G-Halloysite and PP Composites}

Fourier Transform Infrared Spectroscopy (FT-IR). The powder was sheet molded with $\mathrm{KBr}$. The FT-IR analysis was conducted by a Bruker Vector 33 spectrometer. Thirty-two consecutive scans were taken at each sampling time, and their average was stored. Spectra were taken from 4000 to 400 wavenumbers $\left(\mathrm{cm}^{-1}\right)$.

Thermogravimetric Analysis (TGA). TGA was carried out under $\mathrm{N}_{2}$ atmosphere with NETZSCH TG 209F1 at a heating rate of $10^{\circ} \mathrm{C} / \mathrm{min}$ from $30^{\circ} \mathrm{C}$ to $700^{\circ} \mathrm{C}$.

Contact Angle Measurements. Powder of halloysite and g-halloysite were placed in a vacuum oven for $5 \mathrm{~h}$ at $80^{\circ} \mathrm{C}$, and then molded to little discs with diameter of 20 milimeters and thick of 1 millimeter. The disks appeared smooth when inspected by optical microscopy. These asperities of the discs were proved to have no practical effect on reproducibility of contact angle data. Glycerol and deionized water were used for contact angle measurements using Data Physics OCA15.

Scanning Electron Microscopy (SEM). The g-halloysite powders or impact fractured surface of the composites were plated with a thin layer of gold before the observations. The SEM observations were done using LEO1530 VP SEM machine.

Transmission Electron Microscopy (TEM). The specimens were ultramicrotommed into thin pieces of about 10 nanometers in thickness with Leica EM UC6. Then the TEM observations were done using
JEM-100CXII TEM machine at an accelerating voltage of $30 \mathrm{kV}$.

Differential Scanning Calorimetry (DSC). DSC data was measured by a NETZSCH DSC204 F1 using nitrogen as purging gas. The samples were heated to $200^{\circ} \mathrm{C}$ at ramping rate of $20^{\circ} \mathrm{C} / \mathrm{min}$. The sample was kept at $200^{\circ} \mathrm{C}$ for $5 \mathrm{~min}$ to eliminate the thermal history before it is cooled down to $40^{\circ} \mathrm{C}$ at rate of $10{ }^{\circ} \mathrm{C} / \mathrm{min}$. After kept at $40^{\circ} \mathrm{C}$ for $3 \mathrm{~min}$, the sample was reheated to $200^{\circ} \mathrm{C}$ at ramping rate of $10^{\circ} \mathrm{C} /$ $\min$. The endothermic and exothermic flows were recorded as a function of temperature. The crystallinity was calculated based on the endothermic enthalpy $\left(\Delta H_{f}\right)$ as follows:

$$
\text { Crystallinity }(\%)=\frac{\Delta H_{f}}{\Delta H_{f}^{0} \times C}
$$

Where $\Delta H_{f}$ and $\Delta H_{f}^{0}$ are the endothermic enthalpies of the sample and the PP with crystallinity of $100 \%$ respectively. $C$ is the PP weight percentage in the composite. $\Delta H_{f}^{0}$ is $209 \mathrm{~J} / \mathrm{g}$ according to the literature. ${ }^{13}$

Mechanical Properties Determinations. Specimens for the tensile, flexural and impact testing were injection molded and measured according to ISO 527: 1993, ISO 178: 1993 and ISO 180: 1993 respectively. Shimadzu AG-1, Instron 4465 and Zwick pendulum 5113.300 were used to perform the tensile, flexural and impact testing respectively.

\section{RESULTS AND DISCUSSION}

\section{Verification of Interfacial Reactions by Model Com- pound}

The grafting percentage of the silane on the inorganics is generally lower than $1 \mathrm{wt} \%$. Therefore the weight percentage of the silane in the composite is lower than $0.1 \mathrm{wt} \%$ as the halloysite loading in the present study is lower than $10 \mathrm{wt} \%$. As a consequence, direct characterization of interfacial reactions between g-halloysite and PP-g-MAH on molecular scale via vibration spectroscopy such as FT-IR or NMR would be very difficult. To reveal the interfacial reactions in the composite, the model compound, i.e., Z6011 treated PP-g-MAH, was prepared. The reactivity of silane towards to silicate surface is generally accepted. Therefore, the silane Z-6011 is treated with the PP-gMAH under the same condition for the preparation of the g-halloysite to reveal the interfacial reactions during the preparation of the g-halloysite. The model product PP-g-MAH-Z6011 is characterized by FT-IR and the result is shown in Figure 1. As shown, after the treatment the peak of the anhydride groups around $1780 \mathrm{~cm}^{-1}$ is almost disappeared and the intensity of the peak around $1640 \mathrm{~cm}^{-1}$ is substantially increased, 
M. L. DU et al.

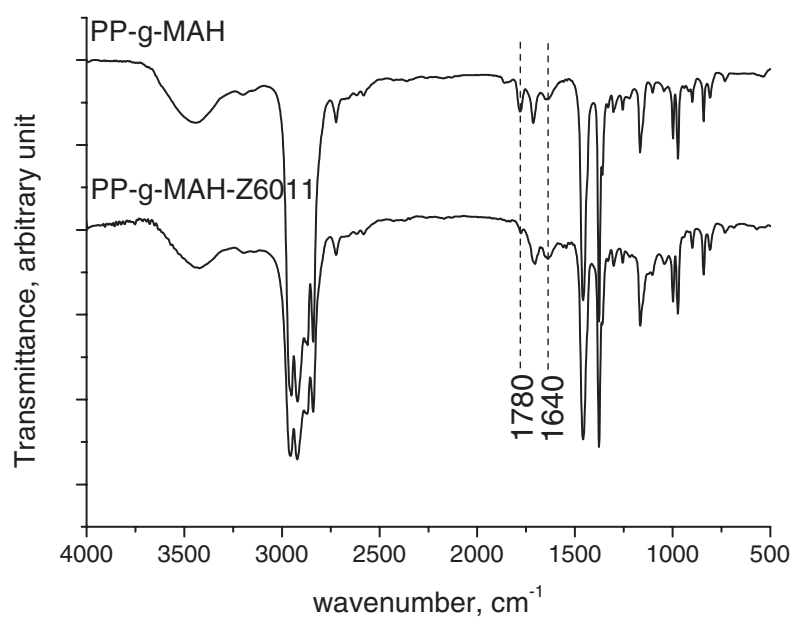

Figure 1. FT-IR spectra of PP-g-MAH before and after treated with Z-6011.

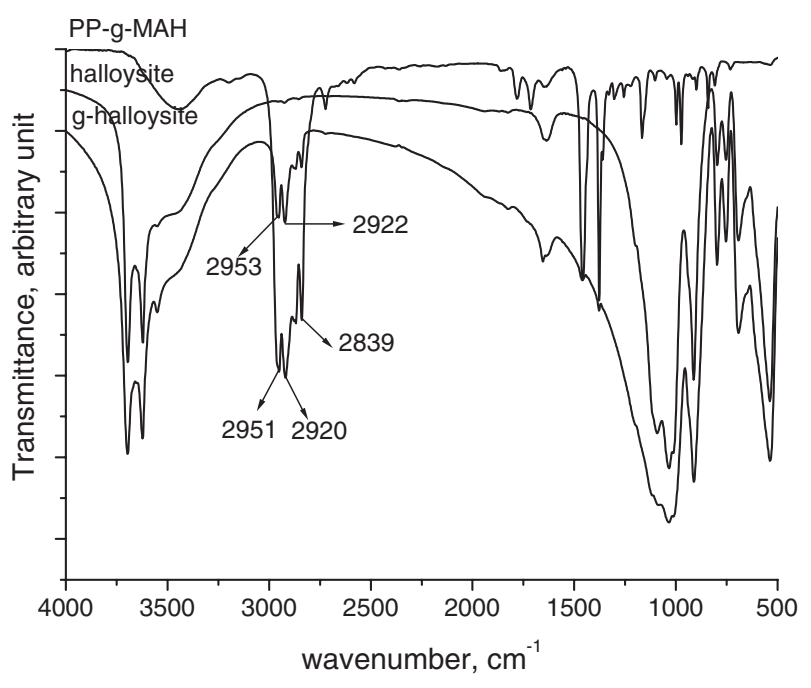

Figure 2. FT-IR spectra of pristine halloysite, PP-g-MAH and g-halloysite.

indicating the formation of the amide groups. It is therefore proved that the grafting of PP chain onto halloysite via the interfacial reactions between PP-gMAH and silane treated halloysite is effective.

\section{Preparation and Characterizations of G-Halloysite}

Figure 2 shows the FT-IR spectra of pristine halloysite, PP-g-MAH and g-halloysite. Typical stretching peaks of $-\mathrm{CH}_{2}-$ and $-\mathrm{CH}_{3}$ around $2900 \mathrm{~cm}^{-1}$ and $2800 \mathrm{~cm}^{-1}$ are observed in the spectrum of g-halloysite. As g-halloysite has experienced three times extraction in hot xylene, this observation suggests the PP-g-MAH is chemically bonded onto the surface of the halloysite. In order to further identify the presence of PP-g-MAH on the surface of g-halloysite, thermogravimetric analysis of pristine and g-halloysite was performed under nitrogen atmosphere. As shown in Figure 3, two distinct weight loss stages are observed

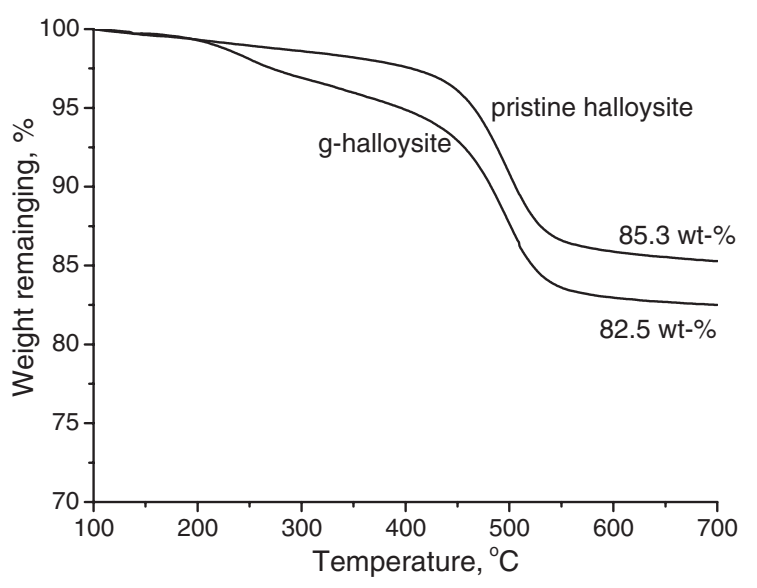

Figure 3. Weight loss curves of pristine halloysite and g-halloysite.

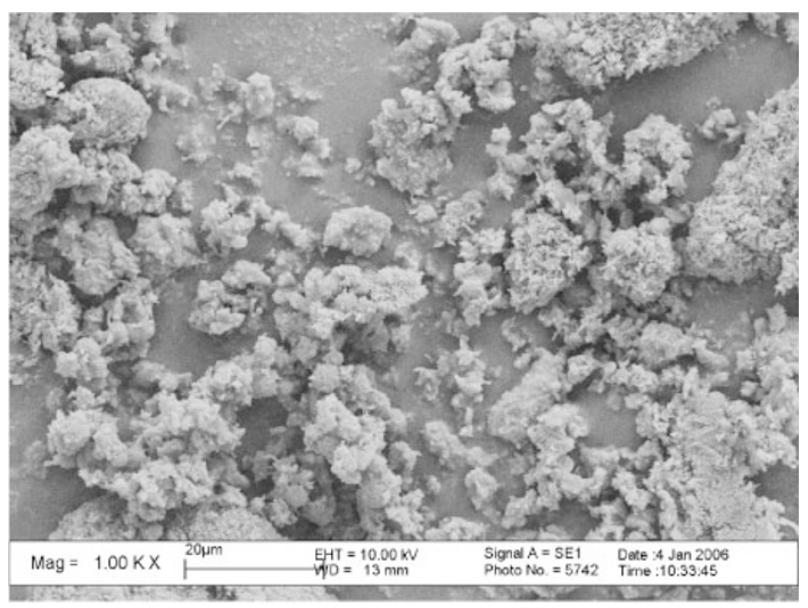

Figure 4. SEM photos of g-halloysite.

in g-halloysite. The stage at lower temperature is attributed to the decomposition of organic species, mainly PP macromolecules, existing on the surface of g-halloysite. The stage at higher temperature is similar to that of the pristine halloysite, owing to the dehydrating of halloysite. The weight loss of the former stage is calculated as $2.8 \mathrm{wt} \%$.

The morphology of the g-halloysite, as indicated in Figure 4, suggests formation of cluster in micrometer size. As the average functionality of amino groups on halloysite and anhydride groups on PP-g-MAH are greater than 2, crosslinking between halloysite and PP-g-MAH occurs and the clusters result. Figure 5 schematically illustrates the preparation process and the structure of g-halloysite. As shown, the silanol groups on the halloysite surface react with silane to form aminized halloysite, converting surface groups from silanols to more reactive amino groups towards to PP-g-MAH. Then the prepared aminized halloysite is reacted with PP-g-MAH by the amidation reaction between amino groups and maleic anhydride groups on PP-g-MAH to form g-halloysite. 


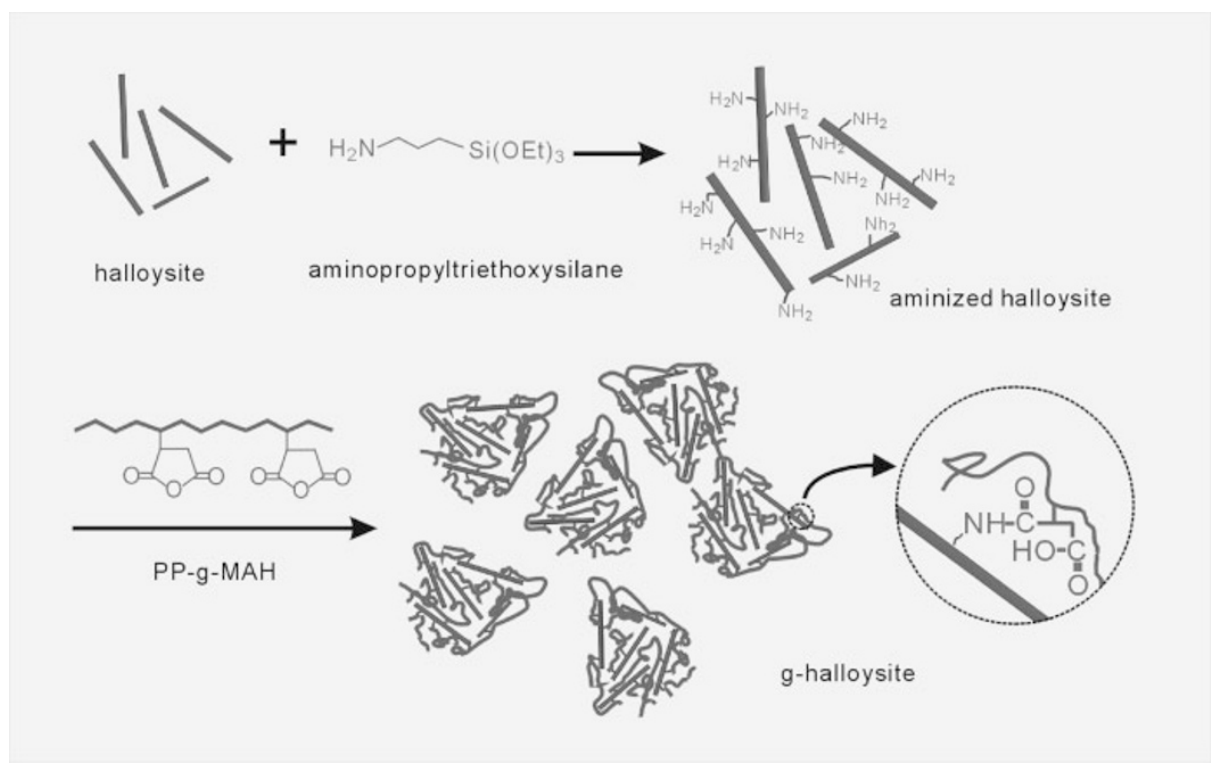

Figure 5. Schematic diagram of preparation process and the structure of g-halloysite.

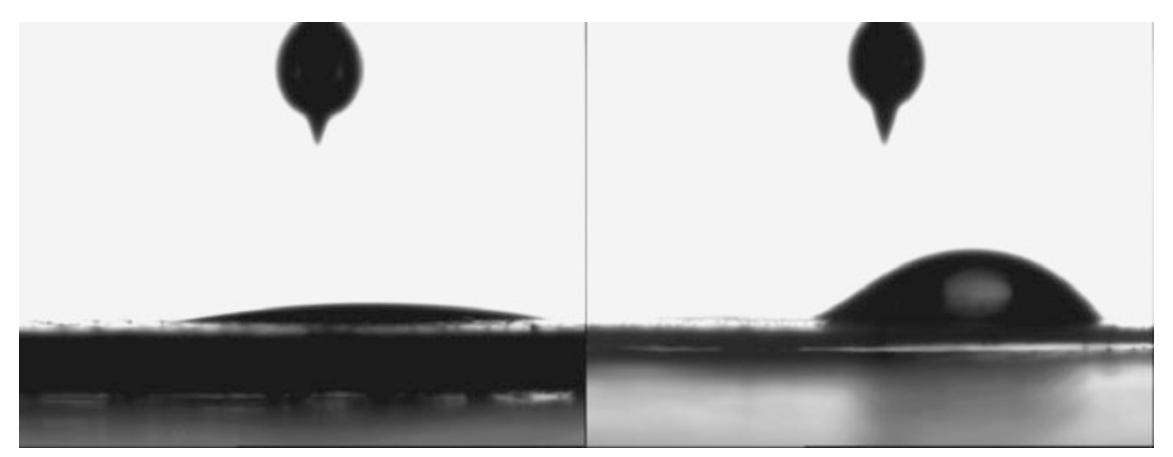

Figure 6. Contact angles of water drops in halloysite (left) and g-halloysite (right) surface.

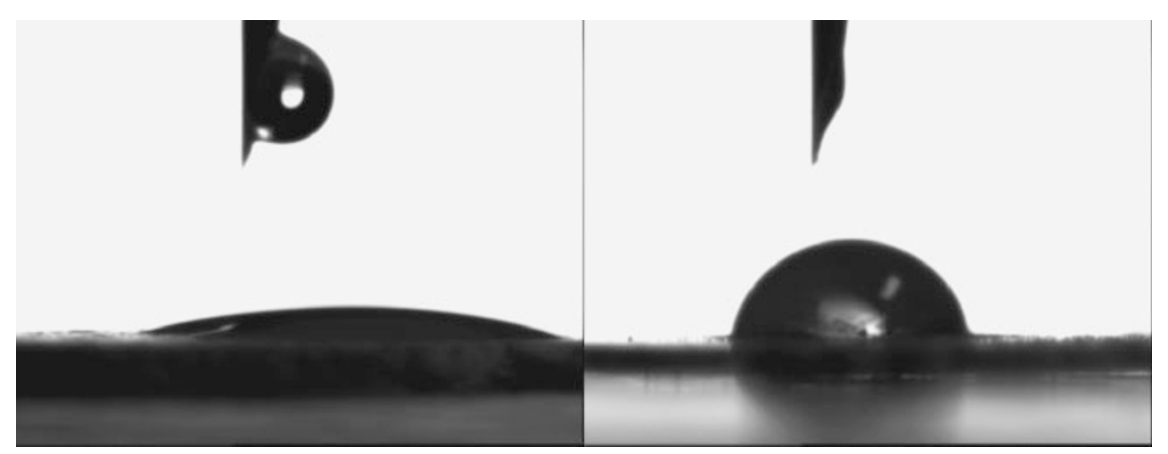

Figure 7. Contact angles of glycerol drops in halloysite (left) and g-halloysite (right) surface.

It is expected that the halloysite would be less polar after the modification by PP molecules. Contact angle between a certain liquid and halloysite or g-halloysite was adopted to evaluate the change in surface polarity. Figure 6 and Figure 7 show the status of water and glycerol on the surfaces of halloysite and g-halloysite. It can be seen that water and glycerol have much greater contact angles on g-halloysite, suggesting substantially reduced polarity. As a consequence, g-halloysite is expected to be more compatible with PP.

\section{Morphology and Properties of PP Composites}

Figure 8 shows the morphology of impact fracture surfaces of $\mathrm{PP} /$ halloysite and $\mathrm{PP} / \mathrm{g}$-halloysite composites. It is obvious that the fracture surface of $\mathrm{PP} / \mathrm{g}$ halloysite composite is much rough compared with that of $\mathrm{PP} /$ halloysite composite, probably being beneficial to the enhancement of impact toughness. At higher resolution, the difference in morphology is much distinct. Unmodified halloysite are dispersed very uniformly, however, in the modified system, hal- 


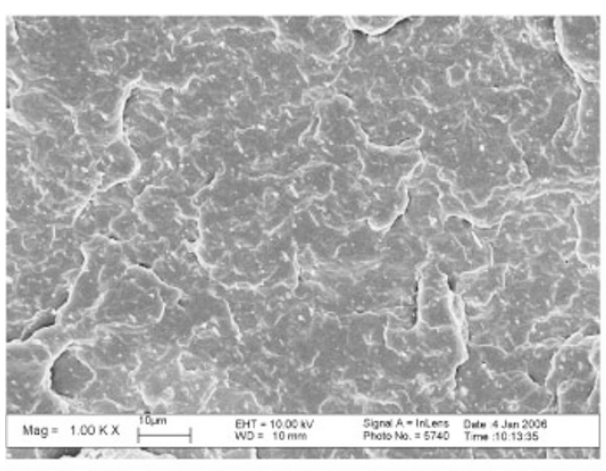

(a)

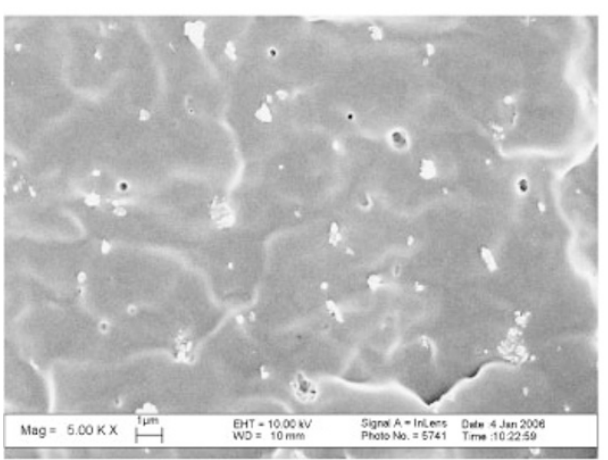

(c)

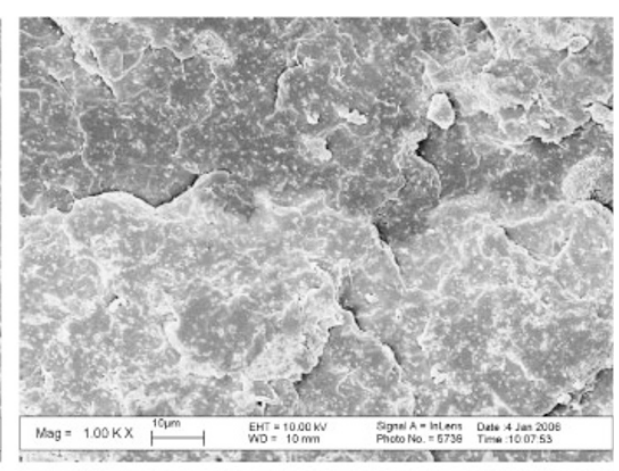

(b)

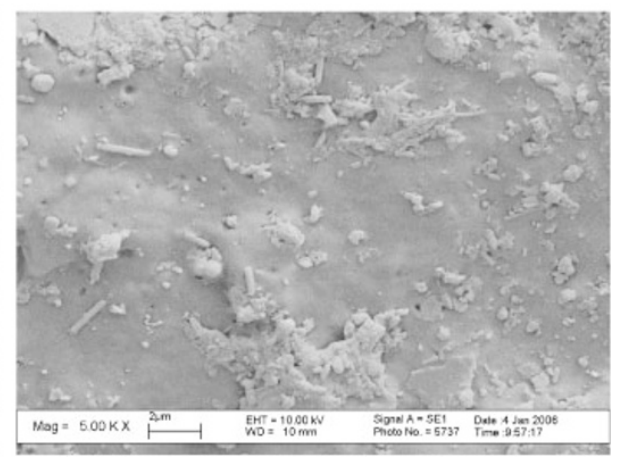

(d)

Figure 8. SEM photos of PP/halloysite $(\mathrm{a}, \mathrm{c})$ and $\mathrm{PP} / \mathrm{g}$-halloysite $(\mathrm{b}, \mathrm{d})$ composite.

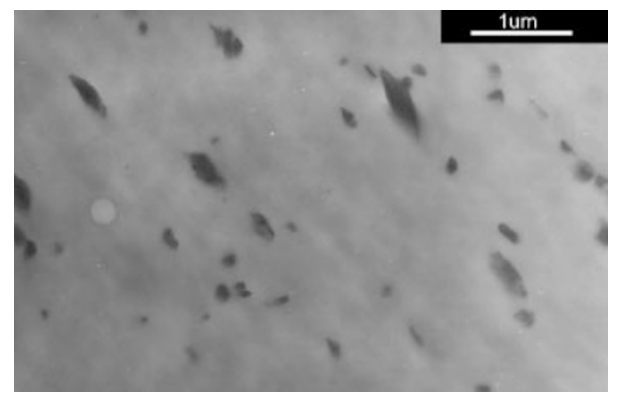

(a)

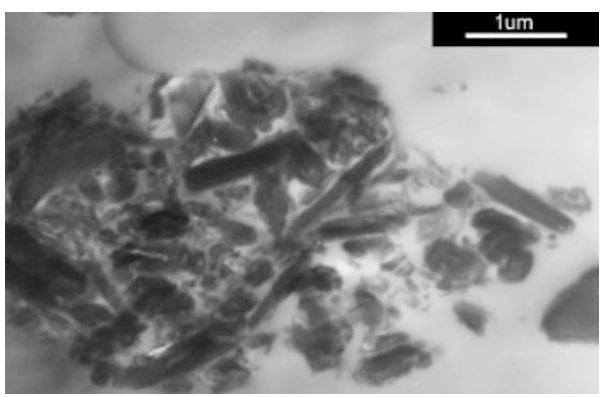

(b)

Figure 9. TEM photos of PP/halloysite composite (a) and PP/g-halloysite composite (b).

loysite are dispersed in the matrix in form of clusters in microscale.

To illustrate the detailed morphology of PP/g-halloysite composite, TEM analysis was performed. As shown in Figure 9, most of the fillers are dispersed in the matrix in the form of clusters, with size in microscale. The cluster is composed of many separated single nanotubes, combined by PP chains. The interface between the nanotube and PP, in this case, is much blurrier, indicating better interfacial adhesion. Consequently the much better interfacial adhesion should be responsible for the changes in the mechanical properties.

PP is typical semicrystalline polymer and the crys- tallization has tremendous effects on the properties of polypropylene, especially the mechanical properties. In order to identify the effects of g-halloysite on the crystallization of polypropylene, DSC experiment was performed. Figure 10 compares the nonisothermal crystallization of neat and the PP composites. It can be seen that inclusion of pristine halloysite leads to slightly increased crystallization temperature of $\mathrm{PP}$, owing to the heterogeneous nucleation. In the $\mathrm{PP} / \mathrm{g}$-halloysite composite, the crystallization temperature is further increased. The increased interactions between PP and halloysite facilitate the ordering of PP segments into crystallite lattice. ${ }^{14,15}$ Table I summarizes the melting enthalpies and crystallinities of 


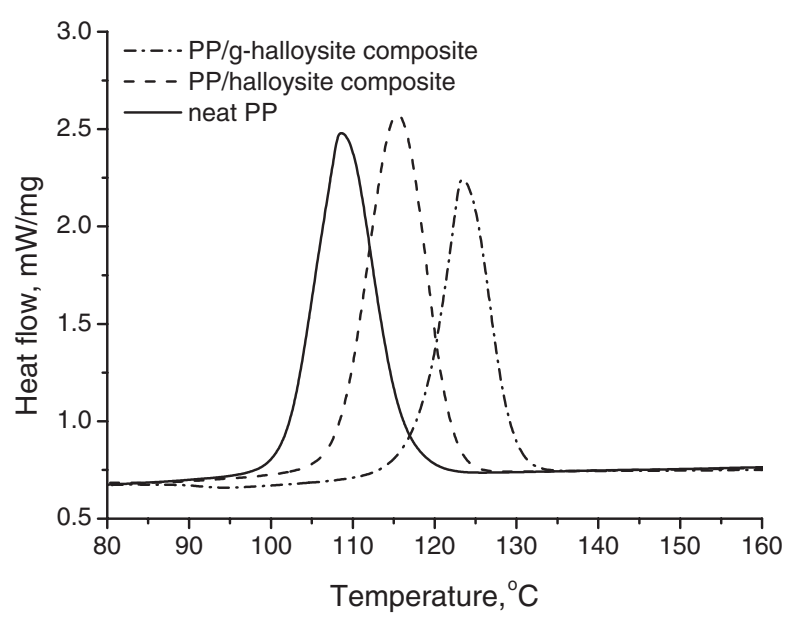

Figure 10. Nonisothermal crystallization of neat PP and PP composites.

Table I. DSC results of neat PP and PP composites

\begin{tabular}{lccc}
\hline \multicolumn{1}{c}{ Samples } & neat PP & $\begin{array}{c}\text { PP/halloysite } \\
\text { composite }\end{array}$ & $\begin{array}{c}\text { PP/g-halloysite } \\
\text { composite }\end{array}$ \\
\hline Melting enthalpy, J/g & 91.7 & 98.1 & 66.5 \\
Crystallinity, \% & 48.3 & 51.7 & 35.0 \\
\hline
\end{tabular}

Table II. Mechanical properties of neat PP and PP composites

\begin{tabular}{lccccc}
\hline Composites & $\begin{array}{c}\text { Filler } \\
\text { content } \\
(\mathrm{phr})\end{array}$ & $\begin{array}{c}\text { Flexural } \\
\text { modulus } \\
(\mathrm{GPa})\end{array}$ & $\begin{array}{c}\text { Flexural } \\
\text { strength } \\
(\mathrm{MPa})\end{array}$ & $\begin{array}{c}\text { Impact } \\
\text { strength } \\
\left(\mathrm{KJ} / \mathrm{m}^{2}\right)\end{array}$ & $\begin{array}{c}\text { Tensile } \\
\text { strength } \\
(\mathrm{MPa})\end{array}$ \\
\hline Neat PP & - & 1.37 & 46.0 & 3.07 & 38.0 \\
PP/halloysite & 10 & 1.56 & 47.9 & 3.47 & 37.4 \\
PP/g-halloysite & 10 & 2.37 & 60.8 & 4.11 & 39.7 \\
\hline
\end{tabular}

neat PP and the PP composites. The crystallinity of the neat PP is about $48.3 \%$. However, the crystallinity of PP/halloysite composite increases to $51.7 \%$, which may be due to higher nucleation rate of halloysite in $\mathrm{PP}$ matrix. For the $\mathrm{PP} / \mathrm{g}$-halloysite composite, although the nucleation takes place at higher temperature, the growth of PP crystallite is substantial depressed by the presence of the relatively bigger clusters. Consequently, the crystallinity of $\mathrm{PP} / \mathrm{g}$-halloysite composite is only $35.0 \%$, substantially lower than that for neat PP.

For polymer composites, generally speaking, more uniform dispersion of the fillers, better performance obtained, higher crystallinity, higher modulus of polymer. This rule, however, does not work in the present system. The mechanical properties especially the modulus of the PP/g-halloysite composite, as shown in Table II, is the highest compared with those for neat $\mathrm{PP}$ or PP/halloysite composite. It is unusual as the PP/g-halloysite composite possesses lower crys- tallinity and "worse" dispersion. This phenomenon should be attributed to the much stronger interfacial bonding between halloysite and PP matrix.

It is generally believed that the fillers with larger size usually serve as stress concentration point in the deformation of polymer matrix, and lead to deteriorated mechanical properties. However, the assembled g-halloysite clusters are actually not the halloysite aggregates. As illustrated in Figure 4, the halloysite were chemically combined by PP chains to form clusters, and the clusters have good interface with PP matrix, which is the key factor for the increase in the mechanical properties of the composites. The detailed mechanism for the increase in mechanical properties is still under investigations.

\section{CONCLUSIONS}

PP chains were chemically grafted onto the surface of halloysite and then the g-halloysite were compounded with PP to form composite. The g-halloysite showed much lower polarity compared with pristine halloysite. The g-halloysite dispersed in PP matrix in the form of micro-scale clusters, which have strong interfacial adhesion with PP matrix. The PP/g-halloysite composite possessed substantially increased mechanical properties compared with neat $\mathrm{PP}$ and $\mathrm{PP} /$ halloysite composite. As the PP/g-halloysite composite had lower crystallinity, the increase in mechanical properties was attributed to the better interfacial bonding of composite. This work provides an effective method for modification of inorganics utilized in polyolefin composites.

Acknowledgment. This work was financially supported by Project of National Science Foundation of China (Grant Number 50603005).

\section{REFERENCES}

1. D. N. Bikiaris, G. Z. Papageorgiou, E. Pavlidou, N. Vouroutzis, P. Palatzoglou, and G. P. Karayannidis, J. Appl. Polym. Sci., 100, 2684 (2006).

2. Z. Ahmad and J. E. Mark, Chem. Mater., 13, 3320 (2001).

3. S. H. Kim, S. H. Ahn, and T. Hirai, Polymer, 44, 5625 (2003).

4. J. Sandler, M. S. P. Shaffer, T. Prasse, W. Bauhofer, K. Schulte, and A. H. Windle, Polymer, 40, 5967 (1999).

5. C. L. Wu, M. Q. Zhang, M. Z. Rong, and K. Friedrich, Compos. Sci. Technol., 65, 635 (2005).

6. M. J. Percy, C. Barthet, J. C. Lobb, M. A. Khan, S. F. Lascelles, M. Vamvakaki, and S. P. Armes, Langmuir, 16, 6913 (2000).

7. K. L. Mittal, "Silanes and other coupling agents," The Netherlands, VSB BV, 1992.

8. B. Pukanszky and Z. Demjen, Macromol. Symp., 139, 93 
M. L. Du et al.

(1999).

9. S. Diez-Gutierrez, M. A. Rodriguez-Perez, J. A. De Saja, and J. I. Velasco, Polymer, 40, 5345 (1999).

10. R. Uotila, U. Hippi, S. Paavola, and J. Seppala, Polymer, 46, 7923 (2005).

11. K. Wang, J. S. Wu, and H. M. Zeng, Acta Polym. Sinca, 697 (2001).

12. M. L. Du, B. C. Guo, and D. M. Jia, Eur. Polym. J., 42, 1362
(2006).

13. J. Brandrup and E. H. Immergut, "Polymer Handbook," 3rd ed., Wiley, New York, 1989, Chapter V.

14. A. Dobreva and I. Gutzow, J. Non-Cryst. Solids, 162, 1 (1993).

15. A. Dobreva and I. Gutzow, J. Non-Cryst. Solids, 162, 13 (1993). 